\title{
The Impact of Promotional Strategies of Pharmaceutical Companies on Doctor's Recommendation of Branded Drugs: An Empirical Study on Pharmaceutical Industry in Sri Lanka
}

\author{
Punchibandara, M. M. T. ${ }^{1}$ \\ Faculty of Graduate Studies, University of Kelaniya, Sri Lanka \\ tharaka910611@gmail.com
}

\begin{abstract}
The study was focused on selected promotional strategies such as medical detailing, providing scientific materials, Sponsorships, continuous medical education programs (CME), and sponsoring clinical meetings conducted by the pharmaceutical companies in order to get recommendations of their products. As a sample, 150 doctors from Colombo, Kandy and Galle, were interviewed with a structured questionnaire. Both descriptive and inferential statistics methods were used to analyze the data. Correlation analysis and multiple regressions were used to test the relationship among the independent and dependent variables. The statistical analysis revealed that there is a significant influence of promotional strategies used by pharmaceutical companies on the recommendation of branded drugs by doctors. Further, it was found that each promotional strategy has different degree of impact on recommendation of branded drugs. Detailing and sampling have significant impact but it is relatively low compared to other factors like continuous meetings, scientific materials and CME.
\end{abstract}

Keywords: Pharmaceutical Industry, Branded Drugs, Promotional Strategies

\section{Introduction}

\section{Background of the Study}

Pharmaceutical companies are developing processes to influence the people who influence the physicians. There are several channels by which a physician may be influenced, including self-influence through research, peer influence, direct interaction with pharmaceutical companies, patients, and public or private insurance companies. These activities are being practiced by the pharmaceutical companies in two ways like creating the pull strategy and

${ }^{1}$ https://orcid.org/0000-0003-1564-8021

Kelaniya Journal of Management | 2017 | Special Issue | Page 55 
push strategy. Pull strategy mainly concentrating on the mass media promotions which has a limited influence on doctors. Push is the main promotional method followed by many countries where promotions are more prominent among doctors. A Country like Sri Lanka is more inclined towards this strategy where the government has not given the provision to do pull strategy (Wendy D. 2007).

Hence, it is very much important to identify the doctor's psychology in order to get the mind share to prescribe a brand. This study touched the key variable, which will help pharmaceutical companies to streamline their marketing strategies and enable them to invest their budget in a proper way to get consistent business throughout the financial year. Also this paper providing basic information of the industry which creates a platform to understand the doctor's perception on branded drugs is common in the Pharmaceutical industry of Sri Lanka.

\section{Literature Review}

In May 2003 the British Medical Journal devoted a special edition on the relationship between doctors and pharmaceutical companies entitled "time to untangle doctors from drug companies" (Moynihan 2003). The theme was relationship between the medical profession and the pharmaceutical industry (Big Pharma). The medical profession in Europe, in conjunction with many social movements, has begun to consider seriously the appropriateness of current relationships between Big Pharma and the health sector. This was occurring in the context of legal actions around corrupt sales practices in Europe such as those against GlaxoSmithKline (GSK) in Germany (Gopal 2002) and Italy (Turone 2003), and the major action against TAP Pharmaceutical Products, Inc in the United States which resulted in a \$875-million-dollar settlement in 2001 (Riccardi 2002).

In this context it is a question that how drug companies promote their products to the medical professionals. According to Jon Buckley (2006), published in a paper article on Electronic Journal of Business Ethics and Organization Studies titling "Pharmaceutical Marketing Time to change" had mentioned two ways, which are creating pull and creating push. As mentioned in this article, pull strategy is much more common in countries like USA and New Zealand where those pharmaceutical companies are given provision to advertise their products on mass media. This is commonly known as Direct to consumer advertisements (DTCA). This was somewhat controversial among the medical professional and health related 
agencies. Flynn (1999) argues that DTCA makes consumers better informed and more sophisticated. In his view consumers are enable, through DTCA, to understand the market better for drugs and the therapeutic options available to them. This view is also shared by Calfee (2002), who argues that consumers can engage in more equitable relationships with health care providers and become partners in their own health care as a result of DTCA. Mintzes et al (2002) found that the consumers had selected drugs through the system having learnt from the advertisements and influenced the physicians to prescribe the same when they go for medication which was responded positively by physicians. The research also found the choice of physicians was influenced and prescribed the same, or otherwise different brands would have been. In contrast to pull strategy, push is the opposite strategy, which is followed by many countries. This was found that more viable and reliable promotional method to a pharma company where many governments do not allow direct advertising to convince consumers (Joan Buckley, 2006).

Separate studies by McInney, Scheidermeyer, Lurie et al (1990), Banks and Mainour (1992) and Chren, Landefeld and Murray (1989) all found that there was a strong correlation between doctors' tendencies to recommend drugs and their receipt of gifts/sponsorship/ nonrelated payment etc. Studies by Wazana (2000), Chren et al (1989) and Thomson, Craig and Barnham (1994) all show that gifts impact on doctors' prescribing practices. Wazana (2000) examined 29 empirical studies of the impact of interactions between the medical profession and Big Pharma. According to this 29 empirical studies that doctors are more keen prescribing the drug with relate to detailing skills, sampling of the products, scientific materials, relationship with the doctor, continuous meeting and CME meeting conducted as a promotional tool by the pharmaceutical companies.

While reviewing the above literature it was found that there is phenomenal relationship among the recommendation of the drug versus promotional strategies implemented by the pharmaceutical companies. Hence researcher looking to identify "To what extent the promotional strategies of pharmaceutical companies will be influential on doctors to prescribe the branded drugs in Sri Lanka.

\section{Hypothesis of the Study}

H1: - The promotional strategies of pharmaceutical companies have a significant influence on doctor's recommendations of branded drugs. 
DOI: http://doi.org/10.4038/kjm.v6i0.7540

H2: - Detailing is the most important promotional strategy which is highly influenced on doctor's recommendation of branded drugs

H3: - Scientific materials are more influenced on doctors' prescription than providing samples.

H4: - Continuous Medical Education (CME) is least significant promotional strategy which has influenced on doctors' prescription.

H5: - Continuous meetings are more significant than sampling as a promotional strategy.

\section{Conceptual Framework}

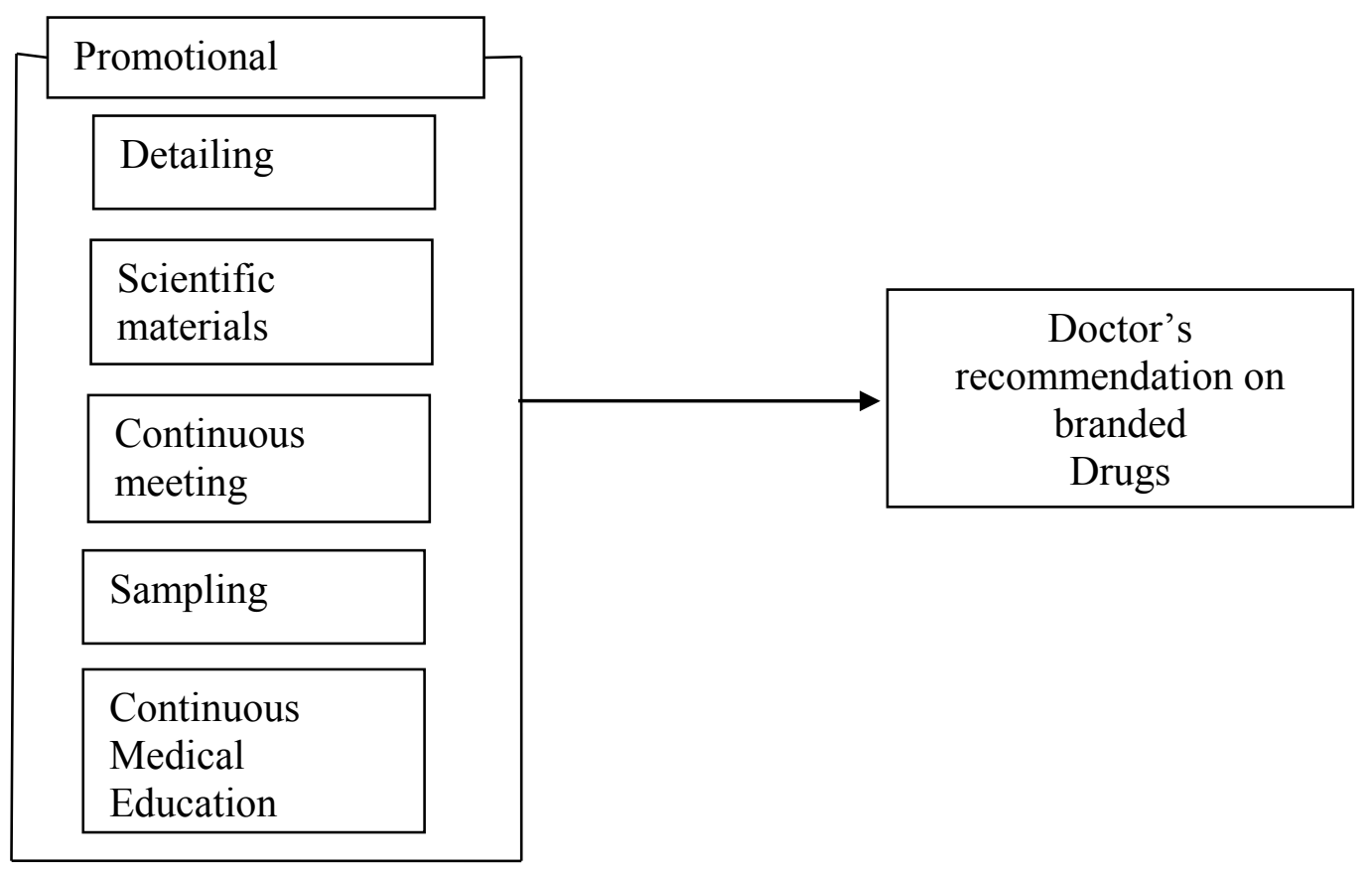

Figure 1: Conceptual Framework

\section{Methodology}

After a preliminary analysis of data, the researcher ascertained that the survey method is the best to collect information for the study. This was mainly because the researcher wanted to know about factors affecting to determine recommendation of branded drugs in Sri Lankan pharmaceutical industry. According to Tull and Hawkins (2005), the survey method is the best approach for collecting this kind of information. 
Krejcie and Morgan (1970) greatly simplified the sample decision table from the population. According to the table, one million populations can be represented as a sample size of 384 . According to the Department of Census and Statistics (2008), active population of doctors in Sri Lanka is 11,023. Even though doctor's population 11,00 plus, only 1000 to 1500 doctors are covered by the pharmaceutical companies in Sri Lanka (IMS annual Report 2017). Since this population homogenous in nature and under the Cochran (1963) table of determining the sample size for $\pm 10 \%$ precision level, with $95 \%$ confidence interval suggested sample size was 99 for the population of 10,000. In the research, samples of 150 respondents were selected from Colombo, Kandy and Galle for the survey under simple random sampling method justified the basis on above criteria. According to the report of IMS survey 2017 Q1, $60 \%$ of the pharmaceutical sales were generated from Colombo, Galle and Kandy. This base gave the researcher to select above areas for the sample collection. Descriptive statistical techniques were utilized to analyze the data. The major descriptive statistical techniques, which were used in this study, are the percentage analysis measurements. Percentage values were highlighted the salient features of collected data, facilitate comparison between variables and enabled the study relationship more readily. Percentage values were used to identify the contribution of various categories for each variable, to identify the nature of influence of each independent variable on store choice behavior and for comparison. In addition, the mean, mode, median, Standard deviation, Correlation analysis and Multiple regression analysis were used for further extensive analysis of data.

\section{Data Processing and Scales}

After the data were collected through questionnaires, they were processed with a view to reduce them to a manageable proportion. In this process researcher used SPSS software package for editing, classification and tabulation. Each question was inserted to SPSS package with defining variables.

\section{Findings and data analysis}

\section{Reliability of Data Collection Instrument}

Cronbach's alpha is the most common form of internal consistency reliability coefficient use by the researches (George and Mallery, 2003). To measure the internal consistency of the items in the questionnaire researcher run reliability test with taking 30 respondents and 
following table indicate the results. First construct was measured by four items and its alpha value identified as 0.673. According to the acceptable measures this value made questions with respect to the items in first construct and researcher reworded the questionnaire and retest to measure the consistency. Later it revealed 0.733 scale value.

Table 1: Reliability Statistics

\begin{tabular}{|c|c|}
\hline Items & Cronbach's Alpha \\
\hline Item 1 & 0.673 later 0.733 \\
\hline Item 2 & 0.885. \\
\hline Item 3 & .762 \\
\hline Item 4 & .738 \\
\hline Item 5 & 1.458 Later 0.867 \\
\hline Item 6 & 0.861 \\
\hline
\end{tabular}

Source: Survey Data 2017

\section{Testing Hypothesis}

H1 The promotional strategies of pharmaceutical companies have significant influence on doctor's recommendation of branded drugs.

Accordingly, from the total of 150 respondents, more than $50 \%$ respondents indicated that all promotional strategies are having significant impact on Doctor's recommendations. According to the hypothetical mean values, if promotional strategies significantly influence on Doctor's recommendations, it should be laid under range of 44.00 and 60.00 . According to the respondents' feedback, the actual mean value is 38.00 . Therefore, it is obvious that promotional strategies have moderate impact on Doctor's recommendations. In addition to that Pearson correlation between promotional strategies and recommendation of branded drugs is 0.520 . It is significant at 0.01 levels (2-tailed). However, it is clear that promotional strategies are positively significant. Therefore, the hypothesis number one can be accepted. 
H2 Detailing is the most important promotional strategy which is highly influenced on doctor's recommendation of branded drugs

According to the findings of data analysis and hypothesis number one promotional strategies are having significant impact on doctors' recommendations. However, promotional strategies consist of detailing, sampling, scientific materials, continuous meetings and continuous medical education programs. The findings revealed that different promotional strategies are having different degree of impact on doctors' recommendations. The actual mean value of detailing is $3.19^{2}$ and relative values of scientific materials, continuous meetings and continuous medical education are higher than that values (Scientific materials- 4.11, Continuous meetings-3.75, and Continues Medical Education-4.005). It is clear that detailing is not most significant promotional strategy of pharmaceutical company. This findings aging rectified from the correlation analysis where that Correlation coefficient of Scientific materials is (0.439) much higher than the correlation coefficient of detailing (0.217). Hence detailing is not the most important promotional strategy to influence the doctors to recommend the branded drugs. Therefore, the hypothesis number two can be rejected.

H3 Scientific materials are more influenced on doctors' prescription than providing samples.

As discussed in the above analysis of the hypothesis, though the promotional strategies have a significant impact on doctors' recommendations each promotional strategy has different degree of impact towards the doctors' influence. The actual mean value of both scientific materials and sampling are 4.11 and 3.16. There is a significant difference between the mean values of scientific materials and sampling. Therefore, it is clear that the scientific materials are more influenced on doctors' prescription than providing samples. This was justified from the correlation analysis where that correlation coefficient of the sampling (0.364) is much lower than the correlation coefficient of scientific materials (0.439). Hence it is clear that scientific materials are more influenced on doctors' prescription than providing samples. Therefore, the hypothesis number three can be accepted.

H4 Continuous Medical Education (CME) is least significant promotional strategy which influenced on doctors' prescription.

\footnotetext{
2 The mean values were recalculated to get the common range with considering number of questions relating to each variable $(9.59 / 03=3.19)$
} 
The findings revealed each promotional strategy has different impact towards the recommendation of the branded drugs by doctors. Especially when researcher compares the actual means of each variable there was a clear difference found among them. This rectified that level of influence made by each variable towards the recommendation of the branded drugs is differ. The actual mean value of the continues medical education is 4.005 and the mean value of the other variables are; detailing-3.19, sampling - 3.16, scientific materials 4.11 , continues meeting -3.75 . The actual mean value of continues medical education is second highest mean compare to other actual mean values. It is not the lowest mean value among the other variables. These findings also justified through correlation coefficients where that correlation coefficient of CME (0.368) is much higher than the detailing $(0.217)$ and sampling (0.364). This data suggested that CME is much more positively correlates than sampling and detailing. Hence, it is clear that continues medical education is not the least significant promotional strategy which influenced on doctors' prescription. Therefore, hypothesis number four is rejected.

H5 Continuous meeting is more significant promotional strategy than sampling

According to the actual mean comparison between sampling and continues meetings, it was found that the mean values much differ from each other and impact towards the doctor's recommendation differs too. The actual mean value of continuous meeting is 3.75 where it is much higher than the sampling mean value, 3.16. This also further explained by the correlation analysis where that correlation coefficient of continues meeting (0.373) is higher than the correlation coefficient of sampling (0.364). This suggested that continues meeting is much positively correlates than sampling. Hence, continuous meeting is more significant promotional strategy than sampling. Therefore, hypothesis number five is accepted.

\section{Multiple Regressions Analysis}

In addition to the descriptive statistics, the researcher further analyzed the impact of promotional strategies on doctor's recommendation of branded drugs with the help of multiple regression model. The model summary, ANOVA table and, Coefficient table are given in table 2, 3 and 4 respectively. 
Table 2: Model Summary

\begin{tabular}{|r|c|c|c|c|}
\hline Model & $\mathbf{R}$ & $\begin{array}{c}\mathbf{R} \\
\text { Square }\end{array}$ & $\begin{array}{c}\text { Adjusted R } \\
\text { Square }\end{array}$ & Std. Error of the Estimate \\
\hline 1 & $.560^{\mathrm{a}}$ & .313 & .289 & .32515 \\
\hline
\end{tabular}

a. Predictors: (Constant), Scientific materials, Sampling, Detailing, CME, Continuous meeting Source: Survey Data 2017

Table 3: ANOVA Table

\begin{tabular}{|rl|r|r|r|r|r|}
\hline \multicolumn{2}{|l|}{ Model } & \multicolumn{1}{c|}{$\begin{array}{c}\text { Sum of } \\
\text { Squares }\end{array}$} & \multicolumn{1}{c|}{ df } & \multicolumn{1}{c|}{$\begin{array}{c}\text { Mean } \\
\text { Square }\end{array}$} & \multicolumn{1}{c|}{ F } & Sig. \\
\hline 1 & Regression & 6.944 & 5 & 1.389 & 13.136 & $.000^{\mathrm{a}}$ \\
& Residual & 15.224 & 144 & .106 & & \\
& Total & 22.168 & 149 & & & \\
\hline
\end{tabular}

a. Predictors: (Constant), Scientific materials, Sampling, Detailing, CME, Continuous meeting. b. Dependent Variable: Doctors Recommendation

Source: Survey Data 2017

Table 4: Coefficient table

\begin{tabular}{|c|c|c|c|c|c|c|}
\hline \multirow{2}{*}{\multicolumn{2}{|c|}{ Model }} & \multicolumn{2}{|c|}{$\begin{array}{c}\text { Un standardized } \\
\text { Coefficients }\end{array}$} & \multirow{2}{*}{$\begin{array}{c}\text { Standardize } \\
\mathrm{d} \\
\text { Coefficient } \\
\mathrm{s} \\
\text { Beta } \\
\end{array}$} & \multirow[b]{2}{*}{$\iota$} & \multirow[b]{2}{*}{ Sig. } \\
\hline & & Beta & Std. Error & & & \\
\hline \multirow[t]{6}{*}{1} & (Constant) & 2.180 & .237 & & 9.190 & .000 \\
\hline & Detailing & & .041 & .008 & .101 & .920 \\
\hline & Sampling & .058 & .049 & .104 & 1.190 & .236 \\
\hline & Continuous meeting & .107 & .041 & .221 & 2.582 & .011 \\
\hline & CME & .082 & .035 & .202 & 2.333 & .021 \\
\hline & Scientific materials & .215 & .063 & .286 & 3.431 & .001 \\
\hline
\end{tabular}

a. Dependent Variable: Doctors Recommendation.

\section{Source: Survey Data 2017}

The results show that the multiple regressions coefficient (R) of the five independent variables and the degree of doctors' recommendation of branded drugs was .56 and the $\mathrm{R}$ 
squire was .313. Therefore, the results suggested that 31 percent of the variance (R Square) in doctors' recommendation of branded drugs has been significantly explained by the group of five independent variables. As shown by the $\mathrm{F}$ value of $13(\mathrm{P}<0.05)$, it is clear that those values are substantiating the main hypothesis. Therefore, the hypothesis one, the promotional strategies of pharmaceutical companies have significant influence on doctor's recommendation of branded drugs can be accepted.

Additionally, the strength of influence of each independent variable would have been on the prescription of branded drugs being addressed and the results are shown in the coefficient table. (See table 4). In analyzing the magnitude of the coefficients, the variables with the largest beta value in absolute (ignoring signs) has greatest influence on the dependent variable. While holding the other independent variables constant, Scientific material on prescription of drugs represent the strongest explanatory variable with a largest standardized beta of .286 and highest $t$ value (3.431). The next strongest explanatory variable with the beta of .221 and $t$ value of 2.582 was continues meeting. This was followed by CME of standard beta value of .202 and t value of 2.333. Therefore, all independent variables help to explain the variance of prescription of drugs by the doctors.

\section{Discussion and recommendation}

Basic job of a medical representative is to meet doctors. He was given other inputs to make that call more professional and productive. In this research it was found that doctors are highly considered on regular meetings of the representatives. With high correlation coefficient and high mean value suggested that continues meeting is highly impact on recommending branded drugs. This revealed that pharmaceutical companies should focus on regular visit of the representative. It is always better to create a field manager/field coordinator level above the representative category to coordinate the regular meetings of doctors. At the same time, it also suggested that to make a small areas or territories to medical reps where that they can increase the frequency of visits to doctors. Especially brand manager should make proper documentation system to get the information from the field. The researcher can suggest some documents such as doctor call reports, doctors profile reports, daily call reports, missing doctor analysis reports, work plans etc.

As a whole the analysis revealed that promotional strategies of pharmaceutical companies had a considerable impact on doctors' recommendation. Therefore, product managers, brand 
DOI: http://doi.org/10.4038/kjm.v6i0.7540

managers, marketing managers should have a balance approach in promoting the drugs to doctors and should concentrates more strategy planning, execution and controlling to reach for substantial and sustainable results.

\section{References}

Banks, J.W., Mainour, A.G. (1992). Attitudes of medical school faculty towards gifts from the pharmaceutical industry. Academic Medicine. Journal of National Center for Biotechnology Information, 67(2), 610-612

Buckley J. (2006). Pharmaceutical marketing-time for change. Electronic Journal of Business Ethics and Organization Studies, 9(2), 1-8

Calfee J. (2002). Public Policy Issues in Direct-to-Consumer Advertising of Prescription Drugs. Journal of Public Policy and Marketing, 21(2), 174-193

Chren M.M., Landefeld, C.S., Murray, T.H. (1989). Doctors, drug companies and gifts. Journal of the Australian Medical Association, 26(2), 3448-3451

Flynn, L.T. (1999). Does direct to consumer advertising of prescription drugs benefit the public's health? - Yes. American Council on Science and Health, 11(4)

Gopal, K. (2002). GSK face bribe charges, changing of the guard. Retrieve from http://www.pharmexec.com/gsk-faces-bribe-charges-changing-guard

McInney W.P., Scheidermeyer D.L., Lurie N. (1990). Attitudes of internal medicine faculty and residents towards professional interaction with pharmaceutical sales representatives. Journal of the Australian Medical Association, 264(13), 1693-1697

Moynihan R. (2003). Drug company sponsorship of education could be replaced at a fraction of its cost. British Medical Journal, 326, 1163, doi:10.1136/bmj.326.7400.1163

Riccardi F. (2002). Healthcare Providers and Pharmaceutical Companies: Is there a prescription for Ethical Relationships? Journal of Health Care Compliance. Jul-Aug, 4-8 
DOI: http://doi.org/10.4038/kjm.v6i0.7540

Thomson, A.N., Craig, B.J., Barnham, P.M. (1994). Attitudes of general practitioners in New Zealand to pharmaceutical representatives. British Journal of General Practice, 44, $220-223$

Tull, D. S., \& Hawkins, D. I. (2005). Marketing Research: Measurement and Method (3 ${ }^{\text {rd }}$ ed.). USA: Macmillan

Turone F. (2003). Italian police investigate GSK Italy for bribery. British Medical Journal, 326,413

Wazana A. (2000). Physicians and the pharmaceutical industry. Is a gift ever just a gift?. Journal of the Australian Medical Association, 283, 373-380

Wendy, D., Herman S. (2007). Healthcare: Pharmaceuticals. Standard \& Poor's Industry Surveys, 175(19), 1-58 